\section{Social capital in fisheries governance}

Fishing policies are typically based on a mix of ecology and economics. It is assumed that fishers will act in line with those considerations. However, that assumption fails to consider the important social and cultural contexts in which fishers operate, and as a result may limit the policies' effectiveness. It is important that regulations recognize and build upon the often unwritten rules and norms of fisher culture in order to secure community support.

For fishery regulations to be followed, compliance is more likely to occur when there is "buy-in" from the community. One way to examine the role of buy-in, and how it is achieved, is through studying the culture of a fishing community. That includes its knowledge, beliefs, and values, as well as how open to change each of these elements is. Previous research has suggested that cultural change may be necessary to achieve conservation goals in certain communities.

The author of this paper examined a small-scale fishery in the United Kingdom where proposed Marine Conservation Zones (MCZs) were opposed by the local fishing community. The study aimed to better understand the community's culture, particularly why the MCZs had been opposed.

The Llŷn peninsula in North Wales is home to a small-scale inshore coastal fishery targeting primarily lobster and scallops. The author conducted interviews with fishers and their family members, with a total of 35 participants ranging in age from 18 to 75 . In 2012, several small areas along the peninsula's coastline were proposed by Welsh officials for designation as highly-protected MCZs in which fishing would be off-limits. However, the local community opposed the designations and the plan was later cancelled.

For the community studied, one of the key aspects of being accepted culturally as a "good fisher" is by complying with community mores and other unwritten "rules of the game." Complying with these community norms accrues social capital for fishers. This social capital allows fishers to earn and assert their own fishing territories. Such territories are established out of respect rather than an explicit contract. The existence of these territories - some of which overlapped with the proposed MCZs - were the most commonly reported reason for opposing the protected area. Loose, continually-evolving fishing territories are largely incompatible with a prescriptive, map-based regulatory framework, such as that of the proposed MCZ. Furthermore, fishers' sense of self was tied to demonstrating their skills at fishing and the notion of trying out new fishing areas in future years as part of that skillset - thus putting their culture at risk if their freedom of movement were restricted. And fishing territories in the community also tend to be transferred to offspring, so closing off areas to fishing could disrupt familial ties in this traditional occupation.

Despite their opposition to the MCZs, however, the fishers largely engaged in voluntary sustainable fishing practices - namely ones that did not infringe on established cultural norms. Per regulation, lobsters with a "v-notch" in the tail cannot be harvested, and in previous years fishers were paid to incise a v-notch on lobsters carrying eggs, thus ensuring the lobsters could hatch more young. When the payments to apply v-notches lapsed, the fishers nonetheless continued to do so to ensure a sustainable population for harvest. Fishers primarily cited the future, particularly their wish for their children to be able to fish in this same area, as the reason for applying v-notches voluntarily.
This is a summary of: Examining the 'cultural sustainability' of two different ways of governing fishing practices

Accessible at: https://marxiv.org/zb6fq

Author:

Madeleine Gustavsson

Added to MarXiv:

April 2018

Published: Marine Policy, 2018

Suggested Citation: Social capital in fisheries governance. OCTO (2018). DOI: $10.17605 / O S F . I O /$ THBN6

See more MarXiv summaries at https://www.marxivinfo.org/ summaries

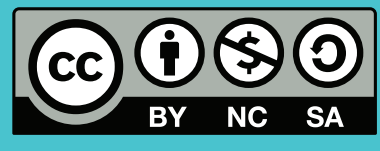

MarXiv is an ОСТO Initiative

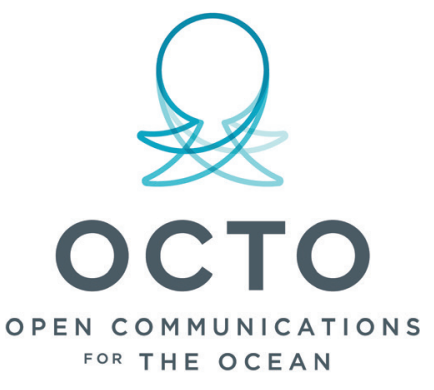

